Fixed Point Theory, 21(2020), No. 2, 495-506

DOI: $10.24193 /$ fpt-ro.2020.2.36

http://www.math.ubbcluj.ro/ nodeacj/sfptcj.html

\title{
MEANS AND CONVERGENCE OF SEMIGROUP ORBITS
}

\author{
ALEKSANDRA GRZESIK*, WIESŁAWA KACZOR**, TADEUSZ KUCZUMOW*** \\ AND SIMEON REICH**** \\ *Wydział Matematyki i Fizyki Stosowanej, Politechnika Rzeszowska \\ 35-959 Rzeszów, Poland \\ E-mail: a.grzesik22@gmail.com \\ **Instytut Matematyki, UMCS, 20-031 Lublin, Poland \\ E-mail: wkaczor@hektor.umcs.lublin.pl \\ *** Instytut Matematyki, UMCS, 20-031 Lublin, Poland \\ E-mail: tadek@hektor.umcs.lublin.pl \\ **** Department of Mathematics, The Technion - Israel Institute of Technology \\ 32000 Haifa, Israel \\ E-mail: sreich@tx.technion.ac.il
}

\begin{abstract}
In this paper we prove the following general theorem. Let $\left(E,\|\cdot\|_{E}\right)$ be a uniformly convex Banach space, and let $C$ be a bounded, closed and convex subset of $E$. Assume that $C$ has nonempty interior and is locally uniformly rotund. Let $\mathcal{F}$ be a commutative nonexpansive semigroup acting on $C$. If $\mathcal{F}$ has no fixed point in the interior of $C$, then there exists a unique point $\widetilde{x}$ on the boundary of $C$ such that each orbit of $\mathcal{F}$ converges in norm to $\widetilde{x}$. We also establish analogous results for semigroups and mappings which are asymptotically nonexpansive in the intermediate sense.

Key Words and Phrases: Asymptotically nonexpansive in the intermediate sense, fixed point, iterates, locally uniformly rotund set, nonexpansive mapping, semigroup of mappings, uniform convexity.
\end{abstract}

2010 Mathematics Subject Classification: 41A65, 47H10, 47H20.

Acknowledgments. The fourth author was partially supported by the Israel Science Foundation (Grants No. 389/12 and 820/17), the Fund for the Promotion of Research at the Technion and by the Technion General Research Fund.

\section{REFERENCES}

[1] H. Brézis, Monotonicity methods in Hilbert spaces and some applications to nonlinear partial differential equations, Contributions to Nonlinear Functional Analysis, Academic Press, New York, 1971, 101-156.

[2] F.E. Browder, Nonexpansive nonlinear operators in a Banach space, Proc. Nat. Acad. Sci. U.S.A., 54(1965), 1041-1044.

[3] R.E. Bruck, T. Kuczumow, S. Reich, Convergence of iterates of asymptotically nonexpansive mappings in Banach spaces with the uniform Opial property, Colloq. Math., 65(1993), 169-179.

[4] J.A. Clarkson, Unifomly convex spaces, Trans. Amer. Math. Soc., 78(1936), 396-414.

[5] M.M. Day, Ergodic theorems for Abelian semigroups, Trans. Amer. Math. Soc., 51(1942), 399412. 
[6] M.M. Day, Amenable semigroups, Illinois J. Math., 1(1957), 509-544.

[7] M. Edelstein, The construction of an asymptotic center with a fixed point property, Bull. Amer. Math. Soc., 78(1972), 206-208.

[8] K. Goebel, W.A. Kirk, Topics in Metric Fixed Point Theory, Cambridge University Press, 1990.

[9] K. Goebel, S. Reich, Uniform Convexity, Hyperbolic Geometry, and Nonexpansive Mappings, Marcel Dekker, 1984.

[10] A. Grzesik, W. Kaczor, T. Kuczumow, S. Reich, Convergence of iterates of nonexpansive mappings and orbits of nonexpansive semigroups, J. Math. Anal. Appl., 475(2019), 519-531.

[11] N. Hirano, K. Kido, W. Takahashi, Nonexpansive retractions and nonlinear ergodic theorems in Banach spaces, Nonlinear Anal., 12(1988), 1269-1281.

[12] W. Kaczor, T. Kuczumow, S. Reich, A mean ergodic theorem for nonlinear semigroups which are asymptotically nonexpansive in the intermediate sense, J. Math. Anal. Appl., 246(2000), $1-27$.

[13] W. Kaczor, T. Kuczumow, S. Reich, A mean ergodic theorem for mappings which are asymptotically nonexpansive in the intermediate sense, Nonlinear Anal., 47(2001), 2731-2742.

[14] O. Kada, A.T.M. Lau, W. Takahashi, Asymptotically invariant net and fixed point set for semigroup of nonexpansive mappings, Nonlinear Anal., 29(1997), 539-550.

[15] E.S. Kim, W.A. Kirk, A note on Picard iterates of nonexpansive mappings, Ann. Polon. Math., 76(2001), 189-196.

[16] W.A. Kirk, Fixed point theorems for non-Lipschitzian mappings of asymptotically nonexpansive type, Israel J. Math., 17(1974), 339-346.

[17] W.A. Kirk, L.M. Saliga, Some results on existence and approximation in metric fixed point theory, J. Comput. Appl. Math., 113(2000), 141-152.

[18] W.A. Kirk, N. Shahzad, Fixed points of locally nonexpansive mappings in geodesic spaces, J. Math. Anal. Appl., 447(2017), 705-715.

[19] W.A. Kirk, B. Sims, Convergence of Picard iterates of nonexpansive mappings, Bull. Polish Acad. Sci. Math., 47(1999), 147-155.

[20] A.T.M. Lau, K. Nishiura, W. Takahashi, Nonlinear ergodic theorems for semigroups of nonexpansive mappings and left ideals, Nonlinear Anal., 26(1996), 1411-1427.

[21] A.T.M. Lau, W. Takahashi, Invariant means and fixed point properties for non-expansive representations of topological semigroups, Topol. Methods Nonlinear Anal., 5(1995), 39-57.

[22] A.R. Lovaglia, Locally uniformly convex Banach spaces, Trans. Amer. Math. Soc., 78(1955), 225-238.

[23] J.-J. Moreau, Un cas de convergence des itérées d'une contraction d'un espace hilbertien, C.R. Acad. Sci. Paris Sér. A-B, 286(1978), 143-144.

[24] O. Nevanlinna, S. Reich, Strong convergence of contraction semigroups and of iterative methods for accretive operators in Banach spaces, Israel J. Math., 32(1979), 44-58.

[25] A. Pazy, On the asymptotic behavior of semigroups of nonlinear contractions in Hilbert space, J. Functional Analysis, 27(1978), 292-307.

[26] W. Takahashi, Nonlinear Functional Analysis, Fixed Point Theory and its Applications, Yokohama Publishers, 2000.

[27] C. Zanco, A. Zucchi, Moduli of rotundity and smoothness for convex bodies, Boll. Un. Mat. Ital., $\mathbf{7}(1993), 833-855$.

Received: February 28, 2019; Accepted: May 30, 2019. 